\title{
Influence of scandium fluoride on the structure and phase composition of Al-Si alloy
}

\author{
Anton Khrustalev ${ }^{1, *}$, Alexander Vorozhtsov ${ }^{1}$, Lyudmila Kazantseva ${ }^{1}$, Vladimir Promakhov ${ }^{1}$, Mark Kalashnikov ${ }^{2}$, \\ Dmitriy Eskin ${ }^{3}$, and Irina Kurzina ${ }^{1}$ \\ ${ }^{1}$ National Research Tomsk State University, 63405036 Lenin Avenue, Tomsk, Russia \\ ${ }^{2}$ National Research Tomsk Polytechnic University, 63405030 Lenin Avenue, Tomsk, Russia \\ ${ }^{3}$ Brunel University, Kingston Ln, Uxbridge UB8 3PH, London, United Kingdom
}

\begin{abstract}
The composition and the microstructure of A356 alloy, obtained by means of addition of scandium fluoride into the melt, were studied. The influence of the amount of the introduced component on the material structure was researched.
\end{abstract}

\section{Introduction}

At present, metal-matrix composites (MMC), based on aluminum hardened by nonmetallic particles, are of great interest in different branches of technology owing to high specific strength, hardness, wear resistance, etc. [1$3]$. Casting is one of the most universal methods of manufacture of such materials. Industrial alloy of A356 grade (Al-Si system, a foreign analogue of domestic alloy AK7) can be applied as a matrix for MMC. Alloy A356 belongs to the category of cast alloys and possesses enhanced welding, mechanical properties, and mechanical characteristics, is corrosion resistant, being also applied in automobile and aerospace industries [4]. Micro- and nanodimensional particles of oxides, carbides, borides, etc. based on aluminum can be used as hardening particles for obtaining MMC. [5]. Nonmetallic particles impede the movement of dislocations and can harden effectively an aluminum matrix during deformation in a wide range of temperatures. At the same time, the hardening effect is determined by the size, concentration, and distribution of particles in the material volume. In a number of works, high efficiency of application of nonmetallic particles $\mathrm{Al}_{2} \mathrm{O}_{3}$ and $\mathrm{SiC}$ was noted [6-7].

An optimal set of parameters of introduction of particles into the alloy can allow reaching the following parameters: high yield point, tensile strength, and Young's modulus, as well as an opportunity of preserving mechanical properties up to $250^{\circ} \mathrm{C}$. There is a multitude of works in the field of hardening of aluminum alloys by microparticles with a size up to $10 \mu \mathrm{m}$, from which it follows that the content of particles in such materials is quite great and equals from 5 to $20 \%$ [8]. The undertaken studies [9-10] allow suggesting that a reduction of an average particle size up to several tens of nanometers will make it possible to improve the MMC properties based on aluminum with a significantly far less content (less than $1 \mathrm{wt} . \%$ ) of particles.
It is known [11-12] that direct introduction of nonmetallic particles (in particular, nanodimensional ones) into liquid metal is a laborious process due to bad wettability, susceptibility of nanoparticles to agglomeration and floatation. This problem can be eliminated when applying external action, including ultrasonic treatment, to the metal melt, which allows efficiently fragmentizing agglomerates of nanoparticles and distributing them in the melt volume.

In work [13], the microstructure and mechanical characteristics of aluminum alloy A356, hardened by nanoparticles of scandium trifluoride with a negative coefficient of thermal expansion, were studied. High efficiency of using modifiers based on scandium fluoride and additional treatment by ultrasound was demonstrated. The studies showed that introduction of fluoride nanoparticles by means of ultrasound treatment allows improving the microstructure and enhancing mechanical characteristics of the initial alloy. At the same time, as it was shown, both hardness and plasticity of the alloy increased. An assumption was made about possible contribution of several mechanisms (load shifting effect, Hall-Petch relationship, Orowan mechanism and difference in CTE between particles and the matrix) to the process of alloy hardening. However, the question of the alloy microstructure, peculiarities of the phase composition, obtained by introduction of scandium fluoride into the melt, remains open. The purpose of the paper is to research the influence of the structure and the phase composition on mechanical characteristics of aluminum alloy A356, obtained by introduction of scandium fluoride into the melt and additional treatment by ultrasound.

\section{Materials and research methods}

To improve wettability, nanopowder $\mathrm{ScF}_{3}$ was preliminary mixed with aluminum powder (an average

* Corresponding author: tofik0014@,mail.ru 
particle size is $\sim 20 \mu \mathrm{m})$ in the ultrasonic bath for 10 minutes. After mixing, the powder mixture was dried in the air, and then it was sieved. The nanoparticles' content in the powder mixture was 20 wt. $\%$. Before introduction of the aluminum alloy into the melt, the powder mixture was placed into a thin metal shell for obtaining a rod shape (Figure $1 \mathrm{a}$ ) and was heated in the furnace up to $200^{\circ} \mathrm{C}$.

The finished ligature was introduced into a zone of ultrasonic cavitation of the melt as Figure $1 \mathrm{~b}$ shows.

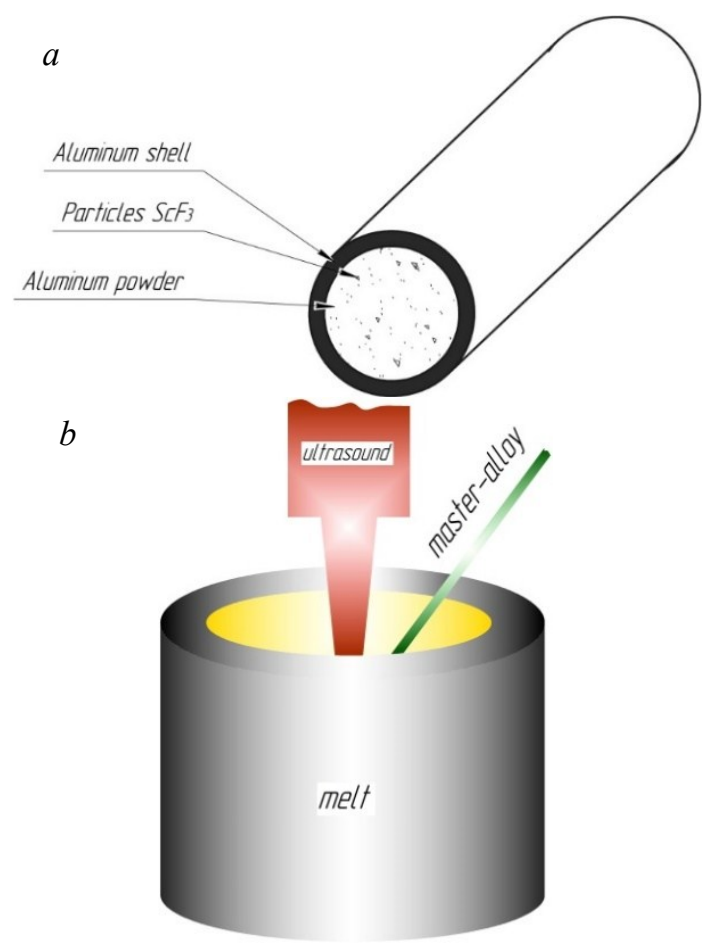

Fig. 1. Ligature $\mathrm{Al}-\mathrm{ScF}_{3}$ (a) and a scheme of ligature introduction into the melt (b).

The alloy based on aluminum A356 was melted in the graphite crucible with a total volume of the melt equal to $500 \mathrm{~g}$. After that, additional ultrasonic degassing of the melt at a temperature of $760{ }^{\circ} \mathrm{C}$ was conducted for 1 minute. Ultrasonic treatment was carried out using a water-cooled magnetostriction transducer with an operating power of $5 \mathrm{~kW}$ and a frequency of $17.1 \mathrm{kHz}$. Then the ligature of $\mathrm{Al}-20$ wt. $\% \mathrm{ScF}_{3}$ was introduced into a zone of ultrasonic cavitation. After introduction of the ligature, the melt was treated by ultrasound during 2 minutes at a temperature of $720-740{ }^{\circ} \mathrm{C}$. Then the obtained mixture was poured into a steel chill mold at a pouring temperature of $710{ }^{\circ} \mathrm{C}$ (casting temperature). In the work, samples with a content of scandium fluoride, introduced into the melt in the amount of 0.2 and $1 \mathrm{wt} . \%$, were obtained. The initial sample was manufactured using analogous parameters of treatment, but without ligature introduction (scandium fluoride).

The microstructure and the elemental composition of the obtained alloys were studied by the method of transmission electron microscopy on thin foils (TEM, "JEM-2100F") at an accelerating voltage of $200 \mathrm{kV}$ with an attachment "JOEL" for energy-dispersive spectrum microanalysis. Differential scanning calorimetry
(NETZSCH STA $409 \mathrm{PC} / \mathrm{PG}$ ) was conducted at a heating/cooling rate of $10^{\circ} \mathrm{C} / \mathrm{min}$.

\section{Results and their discussion}

Figure 2 presents the results of the study of samples of the initial alloy (without the modifier) by the STEM method. The microstructures of unmodified alloys are composed of the interdendritic eutectic matrix $(\alpha-\mathrm{Al}+$ eutectic $\mathrm{Si}$ ) and the $\alpha$-Al matrix grains. The primary $\alpha$ phases are embedded in the eutectic matrix. In the sample, there are matrix aluminum grains and silicon precipitations that are separate coarse needle-shaped in the eutectic region. The wafers have an elongated shape and are located on the grain boundary.
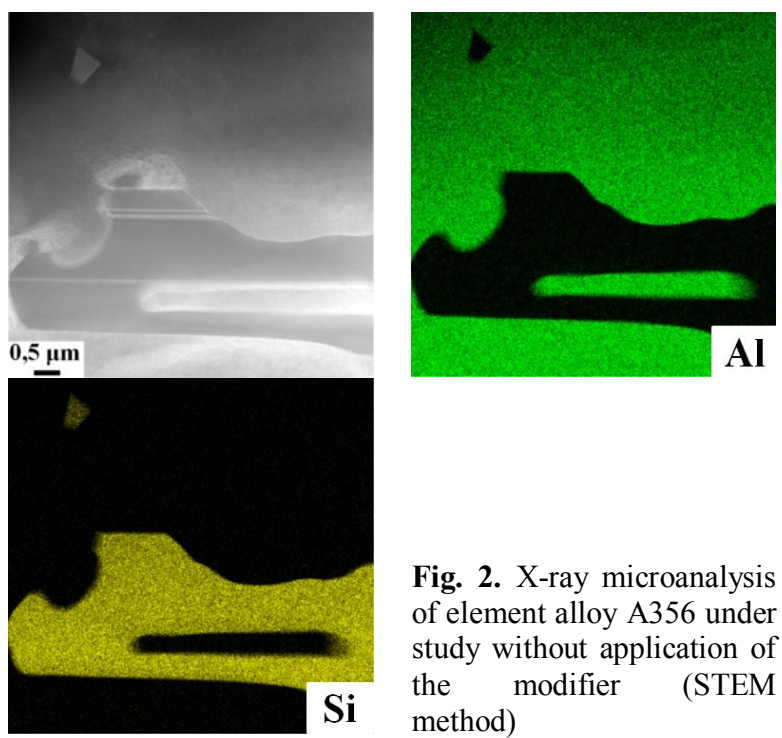

Fig. 2. X-ray microanalysis of element alloy A356 under study without application of the modifier (STEM method)

During commercial melting, feedstock can contain admixtures, in particular, iron that is an accompanying element in the technical aluminum and can exert a significant influence on the crystallisation process and the phase composition. Presence of iron up to (1 wt. \%) in the alloy leads to formation of intermetallic phases in the eutectic interdendritic region. It was established the formation of the traces AlFeSi-phases. Localization, the composition and the form of ternary iron-containing phases are increasingly determined by the concentrated composition and the ratio of the components in the melt.

When introducing scandium fluoride into the melt, the melt structure changes significantly. At high temperatures of the melt, decomposition of fluoride is accompanied by formation of high concentration of nucleation points. The size of $\alpha-\mathrm{Al}$ phase changes slightly compared with the Si and the eutectic matrix.

The eutectic silicon, which is long interconnected and coarse needle-shaped in the unmodified alloy, turns into a thin acicular structure at 0.2 wt. $\%$ and a coral-like fibrous structure over $1 \mathrm{wt} . \%$. The Si becomes smaller, finer and rounder in the modified alloys with increasing of the Sc addition. When adding 0.2 wt. $\%$ of scandium trifluoride into the melt, silicon precipitates in the form of large and small wafers. It would be resulted mainly from the fact that $\mathrm{Sc}$ poisons the growth sites of silicon 
rather than prevents silicon nucleation. In addition, it also may be due to presence of some intermetallic compounds such as $\mathrm{Fe}_{3} \mathrm{Sc}_{2} \mathrm{Si}_{5}$. The composition of threecomponent phases strongly depends on the local concentration of $\mathrm{Sc}$ at the crystallisation moment. Presence of the ligature, introduced into the melt, can slightly result in local concentration displacements and, accordingly, in the change of the crystallisation processes.

Analysis of atoms' distribution by the STEM method, obtained using nanoparticles $\mathrm{ScF}_{3}$, is shown in Figure 3. Formation of ternary phases in the eutectic region of crystallisation was established. The Figure 4 shows that silicon crystalizes along with the ironcontaining phase.

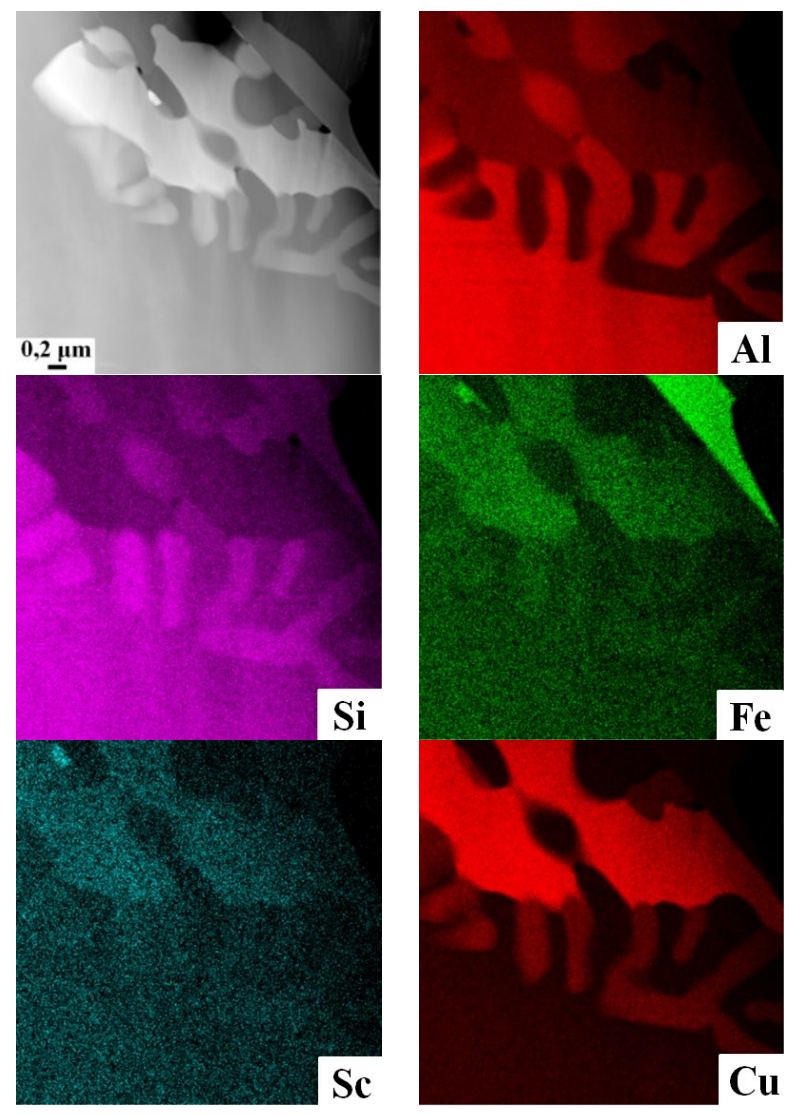

Fig. 3. X-ray microanalysis of elemental alloy A356 under study modified by $0.2 \mathrm{wt} . \% \mathrm{ScF}_{3}$.
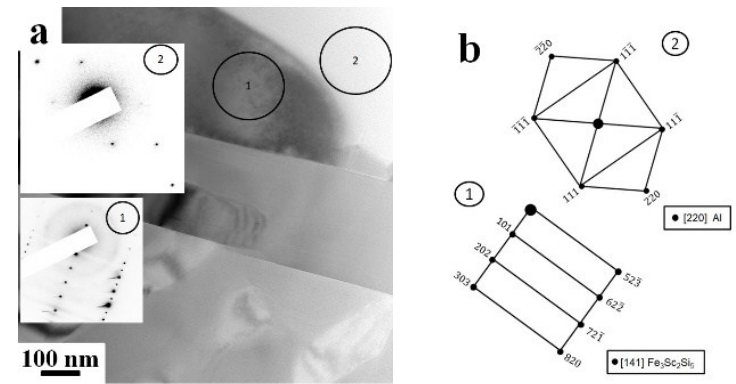

Fig. 4. TEM image of the A356 alloy after the introduction 0.2 wt. $\% \mathrm{ScF}_{3}$ : (a) a bright-field image and microdiffraction pattern; (b) an indexed scheme.

When adding scandium fluoride in the amount of $1 \mathrm{wt} . \%$, it is possible to observe a change in the alloy composition (Figures 5, 6). There are three-component phases, separate precipitations of eutectic and secondary silicon. An increase in the fluoride concentration leads to the fact that formation of phases containing scandium and fluoride in their composition is possible. With the addition of 0.2 wt.\%, the size of eutectic Si becomes finer, where still some plate-like eutectic Si phases are observed. An addition of 1.0 wt.\% Sc results in a more significant modification, the coarse acicular or plate-like eutectic $\mathrm{Si}$ is modified and becomes smooth.
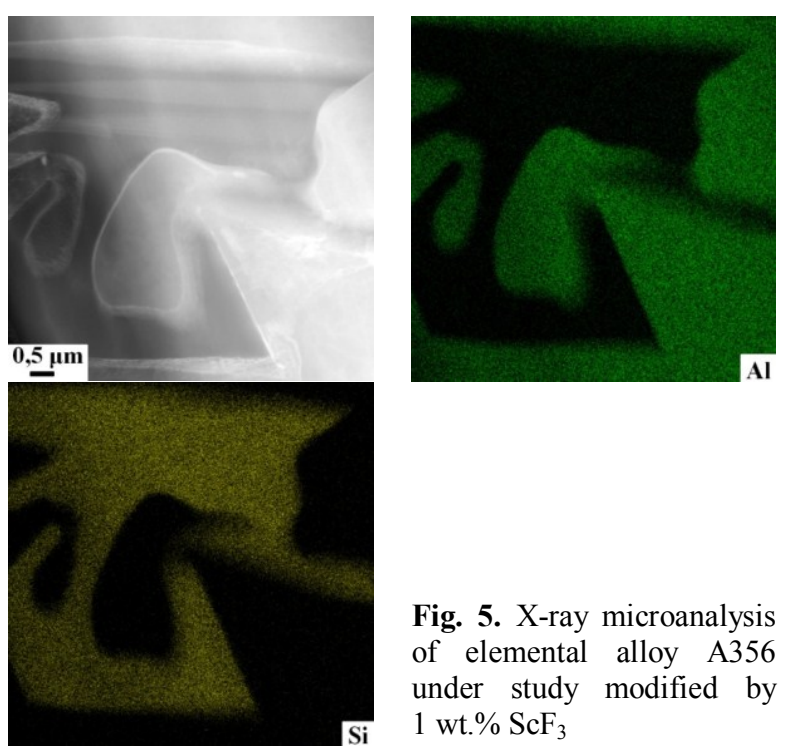

Fig. 5. X-ray microanalysis of elemental alloy A356 under study modified by 1 wt. $\% \mathrm{ScF}_{3}$
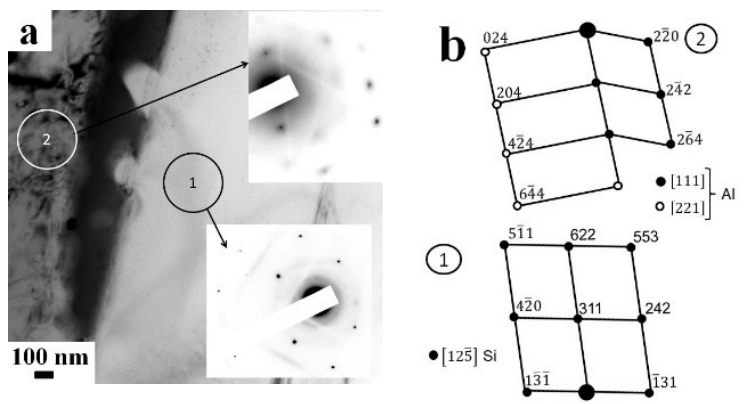

Fig. 6. TEM image of the A356 alloy after the introduction of 1 wt. $\% \quad \mathrm{ScF}_{3}$ : (a) a bright-field image and microdiffraction pattern; (b) an indexed scheme.

It can be seen in Figure 7 that there are two exothermic peaks with $\mathrm{T}_{\max }=584{ }^{\circ} \mathrm{C}$ (I peak) and $\mathrm{T}_{\max }=604{ }^{\circ} \mathrm{C}$ (II peak) for initial alloy, $\mathrm{T}_{\max }=584,2{ }^{\circ} \mathrm{C}$ (I peak) and $\mathrm{T}_{\max }$ $=607{ }^{\circ} \mathrm{C}$ (II peak) for addition of $0.2 \mathrm{wt} . \% \mathrm{ScF}_{3}$ and $\mathrm{T}_{\max }=589,9{ }^{\circ} \mathrm{C}$ (I peak) and $\mathrm{T}_{\max }=610{ }^{\circ} \mathrm{C}$ (II peak) for addition of $1 \mathrm{wt} \% \mathrm{ScF}_{3}$. The I peak can be ascribed to the precipitation binary $\mathrm{Al}-\mathrm{Si}$ eutectic. The II peak is connected with the formation of $\alpha-\mathrm{Al}$ phase. As the concentration of $\mathrm{ScF}_{3}$ increases, a shift in the temperature of the peaks is observed. So at a concentration of 1 wt. $\% \mathrm{ScF}_{3}$, a shift up to $5-10{ }^{\circ} \mathrm{C}$ is observed. The shift of the crystallization temperature could be due to a local change in the concentration of the melt. The displacement of the crystallization temperature leads to a modification of the shape of the crystals of the eutectic region. 


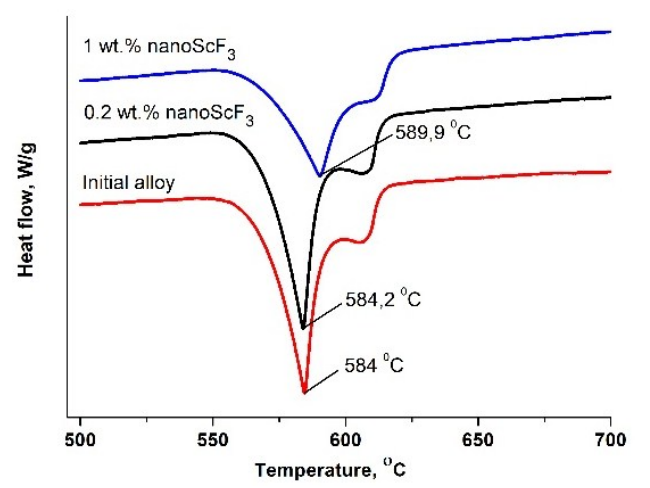

Fig. 7. DSC curves of cooling of A356 with different modifying compositions at a heating temperature of $10^{\circ} \mathrm{C} / \mathrm{min}$.

Various mechanisms have been given for the modification of the eutectic $\mathrm{Si}$. Among those, the impurity-induced twinning mechanism is widely accepted $[14,15]$. It was suggested that the modified $\mathrm{Si}$ contains more twins than unmodified $\mathrm{Si}$ and has a rough micro interface. Each defect on the modified Si surface is a potential site for branching under solidification condition. Therefore the modified $\mathrm{Si}$ is able to bend, curve and split to create a fine microstructure. It was indicated that a value of $1.45-1.65$ is proposed as the ideal ratio of the atomic radius of the impurity-element compared to silicon $\left(r: r_{\mathrm{si}}\right)$ for the element to cause modification. The atomic ratio of $\mathrm{Sc}$ and $\mathrm{Si}$ is close to the ideal value and therefore is predicted to result in a good modification of $\mathrm{Si}$. It seems that $\mathrm{Sc}$ has large negative mixing enthalpy with $\mathrm{Si}$. This causes the crystallization of the eutectic and affects the nucleation rate and growth kinetics of the eutectic Si crystal and results in a good modification effect.

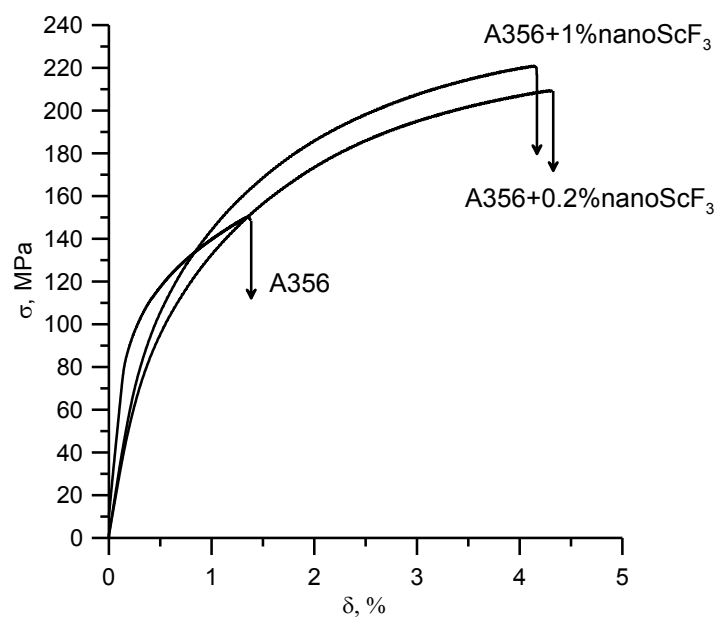

Fig. 8. A stress-deformation diagram of aluminum alloys A356, hardened by nanoparticles of scandium trifluoride.

Mechanical characteristics of the obtained alloys were studied. Curves of dependence of deformation on tension for the obtained samples are given in Figure 8. It is obvious that introduction of 0.2 and 1 wt. $\%$ of nanoparticles in the alloy leads to simultaneous improvement of the yield point, tensile strength and plasticity, but reduces Young's modulus (Figure 8). Besides, the alloy hardness also increases from 63 to 72 HV.

\section{Conclusion}

The effects of $\mathrm{ScF}_{3}$ additions (0, 0.2 wt.\%, 1.0 wt.\%) on the eutectic $\mathrm{Si}$ and Al-phases of A356 alloys were studied by transmission electron microscopy and differential thermal analysis. The experimental results showed that Sc was an effective modifying agent for the eutectic Si. The appropriate addition of Sc (1 wt.\%) had marked effects on shortening the length of needle-like grains. The introduction of 0.2 and 1 wt. $\%$ of nanoparticles in the alloy leads to simultaneous improvement of the yield point, tensile strength and plasticity, but reduces Young's modulus.

\section{Acknowledgments}

This research (project No 8.2.02.2018) was carried out with the support of the Program of increasing the competitiveness of TSU

\section{References}

1. N.Q. Vo, J. Sorensen, E.M. Klier, A. Sanaty-Zadeh, D. Bayansan, D.N. Seidman, D.C. Dunand, JOM. 68, 7 (2016)

2. U. Umer, M. Ashfaq, J.A. Qudeiri, H.M.A. Hussein, S. N. Danish, A.R. Al-Ahmari, Int. J. Adv. Manuf. Technol. 78. 5-8 (2015)

3. E. Naydenkin, I. Mishin, A. Khrustalyov, S. Vorozhtsov, A. Vorozhtsov. Metals. 544, 7 (2017)

4. M. Paradis, M.H. Abdelaziz, H.W. Doty, F.H. Samuel, IJMC. 11, 3 (2017)

5. M.K. Akbari, H.R. Baharvandi, K. Shirvanimoghaddam, Mater.Des. 66 (2015)

6. H.R. Ezatpour, M. T. Parizi, S.A. Sajjadi, G.R. Ebrahimi, A. Chaichi, Mater. Chem. Phys. 178, 119-127 (2016)

7. C. Carreño-Gallardo, I. Estrada-Guel, C. LópezMeléndez, R. Martínez-Sánchez, J. Alloys Comp. V. 586 (2014)

8. X. Teng, W. Chen, D. Huoa, I. Shyhac, C. Lin. Comparison of cutting mechanism when machining micro and nano-particles reinforced $\mathrm{SiC} / \mathrm{Al}$ metal matrix composites. Compos. Struct. V. 203 (2018)

9. S.A. Vorozhtsov, D.G. Eskin, J. Tamayo, A.B. Vorozhtsov, V.V. Promakhov, A.A. Averin, A.P. Khrustalyov. Metall. Mater. Trans. A, 46A (2015)

10. O. Kudryashova, S. Vorozhtsov, M. Stepkina, A. Khrustalev, JOM. 69, 12 (2017)

11. M. Fattahi. et al., J. Mater. Process. Technol. 217 (2015) 
12. S.A. Vorozhtsov, A.P. Khrustalyov, D. Eskin, S.N. Kulkov, N. Alba-Baena, RUPJ. 57, 11 (2015)

13. S. Vorozhtsov, I. Zhukov, V. Promakhov, E. Naydenkin, A. Khrustalyov, A. Vorozhtsov, JOM. 68, 12 (2016)

14. K. Nogita, H. Yasuda, M. Yoshiya, S.D. McDonald et all, J. Alloys Compd., 489, 425 (2010).

15. Lu SZ., Hellawell A., Metall.Mater. Trans. A, 18, 1721 (1987). 